\title{
Revisiting the Challenge of Intentional Value Shift: Reply to Ives and Fischer
}

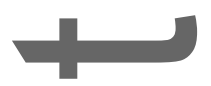

Michael J. Manfredo ${ }^{a^{*}}$, Jeremy T. Bruskotter ${ }^{\mathrm{b}}$, Tara L. Teel ${ }^{\mathrm{a}}$, David Fulton ${ }^{\mathrm{c}}$, Shigehiro Oishi ${ }^{\mathrm{d}}$,

Ayse K. Uskul ${ }^{\mathrm{e}}$, Kent Redford ${ }^{\mathrm{f}}$, Shalom H. Schwartz ${ }^{\mathrm{g}}$, Robert Arlinghaus ${ }^{\mathrm{h}}$, Shinobu

Kitayama, and Leeann Sullivan ${ }^{\mathrm{a}}$

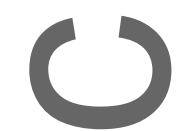

${ }^{a}$ Human Dimensions of Natural Resources, Colorado State University

1480 Campus Delivery, Fort Collins, CO 80523-1480, U.S.A.

${ }^{\mathrm{b}}$ School of Environment and Natural Resources, Ohio State University

210 Kottman Hall, 2021 Coffey Road, Columbus, OH 43210, U.S.A.

${ }^{c}$ Department of Fish, Wildlife and Conservation. Biology, University of Minnesota

135 Skok Hall, 2003 Upper Buford Circle, St. Paul, MN 55108, U.S.A.

${ }^{\mathrm{d}}$ Department of Psychology, University of Virginia

102 Gilmer Hall, PO Box 400400, Charlottesville, VA 22904, U.S.A.

${ }^{\mathrm{e}}$ School of Psychology, University of Kent

Keynes College, University of Kent, Canterbury, Kent CT2 7NP, U.K.

${ }^{\mathrm{f}}$ Archipelago Consulting

PO Box 4750, Portland, ME 04112, U.S.A.

${ }^{\mathrm{g}}$ Department of Psychology, The Hebrew University of Jerusalem

Mount Scopus, Jerusalem 91905, Israel

This is the alt manuscript accepted for publication and has undergone full peer review but has not been thi woh th copyediting, typesetting, pagination and proofreading process, which may lead to differences betw this version and the Version of Record. Please cite this article as doi: 10.1111/cobi.13026.

This article is protected by copyright. All rights reserved. 
${ }^{\mathrm{h}}$ Leibniz-Institute of Freshwater Ecology and Inland Fisheries

Müggelseedamm 310, 12587 Berlin, Germany

${ }^{\mathrm{i}}$ Department of Psychology, University of Michigan

1004 East Hall, 530 Church Street, Ann Arbor, MI 48109-1043, U.S.A.

* michael.manfredo@colostate.edu

Running Head: Intentional Value Shift

Article Impact Statement - Conservation values are unlikely to change through intentional efforts.

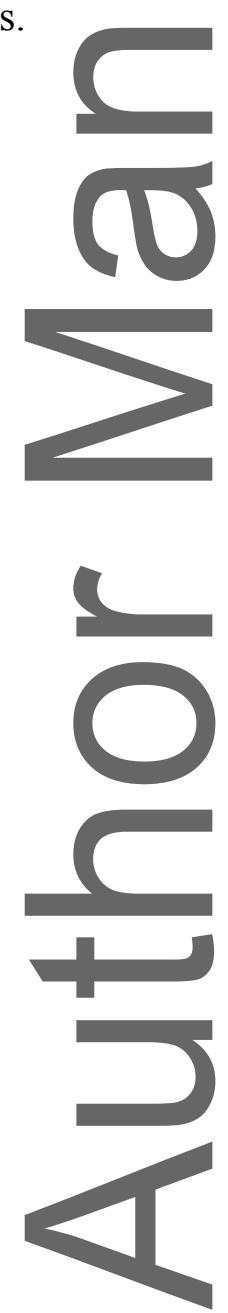

This article is protected by copyright. All rights reserved. 
Manfredo et al. (2017) had a dual purpose: to present a social-ecological systems approach to understanding social values and, given that approach, to describe the difficulty of trying to change society's values to meet sustainability and conservation goals. Ives and Fischer (2017) generally agree with our systems approach. They insist, however, that efforts to change societal values are nonetheless important for achieving sustainability goals. We argue that intentional change in societal values is unrealistic.

Weagree with Ives and Fischer that values are at the root of action. They point out, "culture and values stemming from enlightenment, the industrial revolution, and the principles of capitalism" make it difficult to achieve sustainability in our modern global society. Indeed, beyond the realm of conservation, findings suggest that values play a critical role in determining the success of social, economic, and political development across countries (Harrison \& Huntington 2000). If values could somehow be shifted, that shift might lay a foundation for effective biodiversity conservation and broader sustainability.

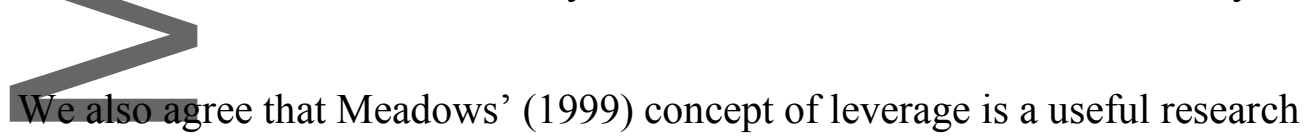
framework for examining ways to influence social-ecological systems and to understand sociocultural change. Abson et al. (2016) propose 6 areas of possible deep leverage. However, recognizing the possibility of leverage does not demonstrate that change is achievable. Accordingly, we suggest that deep-leverage routes, directed at behavior rather than values, would be more fruitful in achieving sustainable societies (e.g., rules of system, structure of information flows). There is an extensive literature on behavior change in the social sciences that could assist in driving such efforts (e.g., Osbaldiston \& Schott 2012). This article is protected by copyright. All rights reserved. 
Finally, we agree that the social sciences can take the lead in helping humans adapt to the growing threats to sustainability and biodiversity conservation. Approaches such as developing a science of intentional behavioral and culture change may be an important step in that direction (Witson et al. 2014; Wilson 2016). This approach would entail a multidisciplinary social science effort guided by an evolutionary framework that recognizes the need foractions to match problems at different scales.

Although we agree with Ives and Fischer on many points, we reach different conclusions based on different views of the problem. Ives and Fisher's disagreement with our conclusion appears to be rooted in the world's desperate need for effective conservation and the belief that if we do not try to change values, we will not know if we can effect change. They express hope for a desired outcome but offer scant research and no actual case studies or other guidance to support their hopes. Rather than hoping or speculating, we proposed that action to achieve social change should be guided by the information science has to offer. We formulated our conclusions based on a synthesis of current thinking and literature about values.

Our contrasting views pose important questions for conservationists, such as to what extent can humans influence the direction of culture? We take an evolutionary perspective. Although values affect intentions and expected behavior, they are backward looking, not forward looking. Yalue formation and adoption at the societal level occurs after changes in cultural practice and behavior. There are strong feedback loops between practice and values, but values do not arise and then spawn new behavior. Rather, new behaviors become advantageous and routine, giving rise to new values. The appearance of new values within a 
population is not the result of intentional deliberation and selection among societal members.

Human agency may be in the process of becoming more important in the evolution of r.

cultures (Bandura 1989). However, we agree with Wilson (2016:190): “To a large extent, cultures work without anyone designing them or knowing how they work."

Human inability to affect cultural shift is reflected in many examples throughout human history that involve forcing change on groups of people. Such efforts have had unpredictable consequences and have been fraught with human suffering. For example, missionary initiatives or military conquests often attempt to impose new norms and values on the converted or the vanquished, as in the case of the many unsuccessful attempts to acculturate Native Americans (e.g., Tinker 1993). In other examples, political leaders such as Stalin (Hoffmann 2003) or those of post-Mao China sought to change cultural thought and practice to accelerate modernization. To illustrate, China implemented the one-child (per couple) birth policy to reduce population growth. Lauded for its proenvironmental outcomes, the primary rationale for this action was to increase the standard of living per capita gross domestic product (Feng et al. 2013). Applying the Abson et al. (2016) framework, this serves as an example of deep leverage because it changed the rules of the system. In doing so, it sought to create a more modernized, economically well-off culture and shift values relating to family structure (Feng et al 2013). Value shift was initiated by changing system rules through a policy that limited reproductive behavior. Although the policy succeeded in reducing fertility rate, it had other unintended impacts, for example, it weakened the tradition of filial (values of respect and caring for elderly) because fewer children were present to care for the elderly (Zhan \& Montgomery 2003; Feng et al. 2014). Likewise, this policy had the This article is protected by copyright. All rights reserved. 
unintended effects of sex-selective abortion, population aging, and violations of human rights. Moreover, the fertility rate decline may have happened even without the one-child (1)

policy due to a demographic transition already underway (Feng et al. 2013). In contemplating intentionatvalue shift, it would be wise to heed the maxim that "all history is the history of unintended consequences" (Cohen 2013).

Ives and Fischer proclaim that value shift need not be "dreamy" or "ideological." But society is clearly a long way from being able to achieve desirable value shifts or even from knowing whether they are possible. One of the most challenging hurdles would be finding a starting point. Realistically, value differences are likely to be intractable and consensus difficult to achieve in a world as diverse as ours, with competing value hierarchies both within andacross societies. Given current conditions, it seems unlikely that such diverse social factions will ever reach agreement regarding the values that should predominate in an ideal world. In the future, as in the past, a significant task of conservation will be understanding, reconciling, and respecting diverse values relating to achieving sustainability and biological diversity.

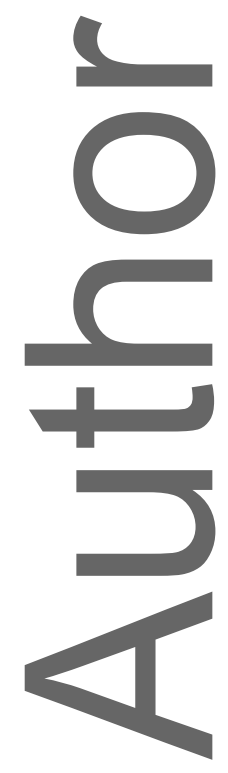

This article is protected by copyright. All rights reserved. 


\section{Literature Cited}

Abson DJ, et al. 2016. Leverage points for sustainability transformation. Ambio 46:30-39.

Bandura A. 1989. Human agency in social cognitive theory. American Psychologist 44:

I1175-1184.

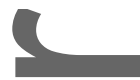

Cohen BR. 2013. The confidence economy: an interview with T. J. Jackson Lears. Public Books, New York.

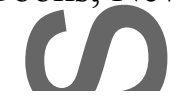

Feng W, Cai Y, Gu B. 2013. Population, policy, and politics: How will history judge China's one-child policy? Population and Development Review 38(1):115-129.

Feng XT, Poston Jr. DL, and Wang XT. 2014. China's one-child policy and the changing family. Journal of Comparative Family Studies 45(1):17-29.

Harrison LE, Huntington SP. 2000. Culture matters: how values shape human progress. Basic Books, New York.

Hoffmann DL. 2003. Stalinist values: the cultural norms of Soviet modernity, 1917-1941.

Cornell University Press, Ithaca, New York.

Ives DI, Fischer J. 2017. The self-sabotage of conservation: reply to Manfredo et al. Conservation Biology: in press.

Manfredo MJ, et al. 2017. Why social values cannot be changed for the sake of conservation. Conservation Biology 31:772-780.

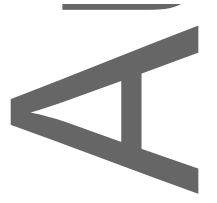

This article is protected by copyright. All rights reserved. 
Meadows D. 1999. Leverage points: places to intervene in a system. The Sustainability

Institute, Hartland, Vermont.Osbaldiston R, Schott JP. 2012. Environmental sustainability and behavioral science: Meta-analysis of pro-environmental behavior experiments. experiments. Environment and Behavior 44:257-299.

Tinker GE 1993. Missionary conquest: the gospel and Native American cultural genocide.

Fortress Press, Minneapolis, Minnesota.

Wilson DS, Hayes SC, Biglan A, Embry DD. 2014. Evolving the future: Toward a science of intentional change. Behavioral and Brain Sciences 37(4):395-416.

Wilson DS. 2016. Intentional cultural change. Current Opinion in Psychology 8:190-193.

Zhan HJ, Montgomery RJ. 2003. Gender and elder care in China: the influence of filial piety (1) and structural constraints. Gender \& Society 17(2): 209-229.

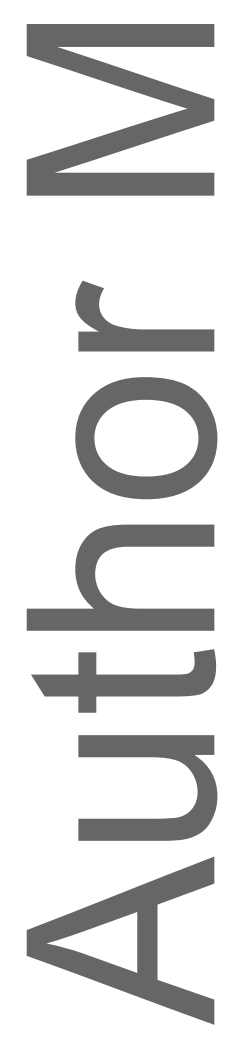

This article is protected by copyright. All rights reserved. 